\title{
Professor E. Pojnar's pioneer studies on isolated protoplasts, their continuation and development. In memory of Professor Edward Pojnar (1919-2011)
}

\author{
Anna Pindel*, Alina Wiszniewska, Barbara Piwowarczyk \\ Department of Botany and Plant Physiology, University of Agriculture in Krakow, Kraków, Poland \\ *Corresponding author: a.pindel@ogr.ur.krakow.pl
}

\begin{abstract}
This paper is dedicated to the memory of Professor Edward Pojnar (1919-2011), Head of the Department of Botany (1974-1990) at the University of Agriculture in Krakow, who initiated research on isolated plant protoplasts in Poland. Studying in Professor E.C. Cocking's Plant Physiology Laboratory at the University of Nottingham, Professor Pojnar became acquainted with the enzymatic method procedure for protoplast isolation. His postdoctoral thesis was published in 1969 as the first paper on protoplast isolation and culture procedures in Poland. The present paper is a survey of Professor Pojnar's research, as well as further studies inspired by his pioneering achievements. Recent research into protoplast technology, focused on the structural changes involved in protoplast regeneration, is also discussed.
\end{abstract}

Key words: plant protoplasts, isolation, cell wall

Plant cells have been exploited as single experimental units since the second half of the $19^{\text {th }}$ century, when a new scientific field, cytology, was developed. It had been preceded by technical progress in microscopy methods and tool development. Although the existence of a plant cell had been proven by Robert Hook as early as 1665 , insight into cell structure was only made possible two hundred years later. The integration of scientific disciplines (biochemistry, physiology, and molecular biology) made it possible to treat a cell as an experimental object in virtually all fields of life sciences, which now allows researchers to observe dynamic changes in cell function, structure or its reaction to external stimuli. Furthermore, in the case of plant material, the isolated protoplasts themselves can be used as experimental objects. Cell-wall degradation, as well as its resynthesis occurring in protoplast cultures allow numerous independent studies to be conducted.

Research into plant protoplasts was started in the Department of Botany at the University of Agriculture in Krakow in 1969 on the initiative of Dr Edward Pojnar upon his return from a scientific internship in Professor E.C. Cocking's Plant Physiology Laboratory at the University of Nottingham. During his study in Great Britain, Pojnar became acquainted with the procedure for protoplast isolation using an enzymatic method (Pojnar et al., 1967; Pojnar and Cocking, 1968), but in order to conduct similar research in his own department he had to arrange a suitable laboratory to work in sterile conditions. He himself constructed a chamber with laminar airflow (Fig. 1A), a device for enzyme filtration, modeled after a Sartorius bacterial filter (Fig. 1B), and a tube equipped with a copper plate, attached to a water bath, to maintain the proper temperature for protoplasts being embedded in agarose medium (Fig. 1C). Edward Pojnar also designed and built himself a timer-switched agitator, which was then installed in a thermostat used for protoplast incubation in enzyme mixture.

E. Pojnar's postdoctoral dissertation ("habilitation") was the first paper describing studies on plant protoplasts to be published in Poland (Pojnar, 1969). Using light and electron microscopy, Pojnar studied the effects of stress induced by isolation from the tissue and the degradation of the cell walls by hydrolytic enzymes (Pectinol or Pectinase) on protoplasts obtained from tomato fruits. Protoplasts kept in a $20 \%$ sucrose solution were rather stable, which suggested their possible regeneration into cells. Pojnar verified this by freezing them in a 3-4 day-old culture for $1 \mathrm{~h}$ at $-20^{\circ} \mathrm{C}$. He found that after thawing the protoplasts had shrunk and protruded 


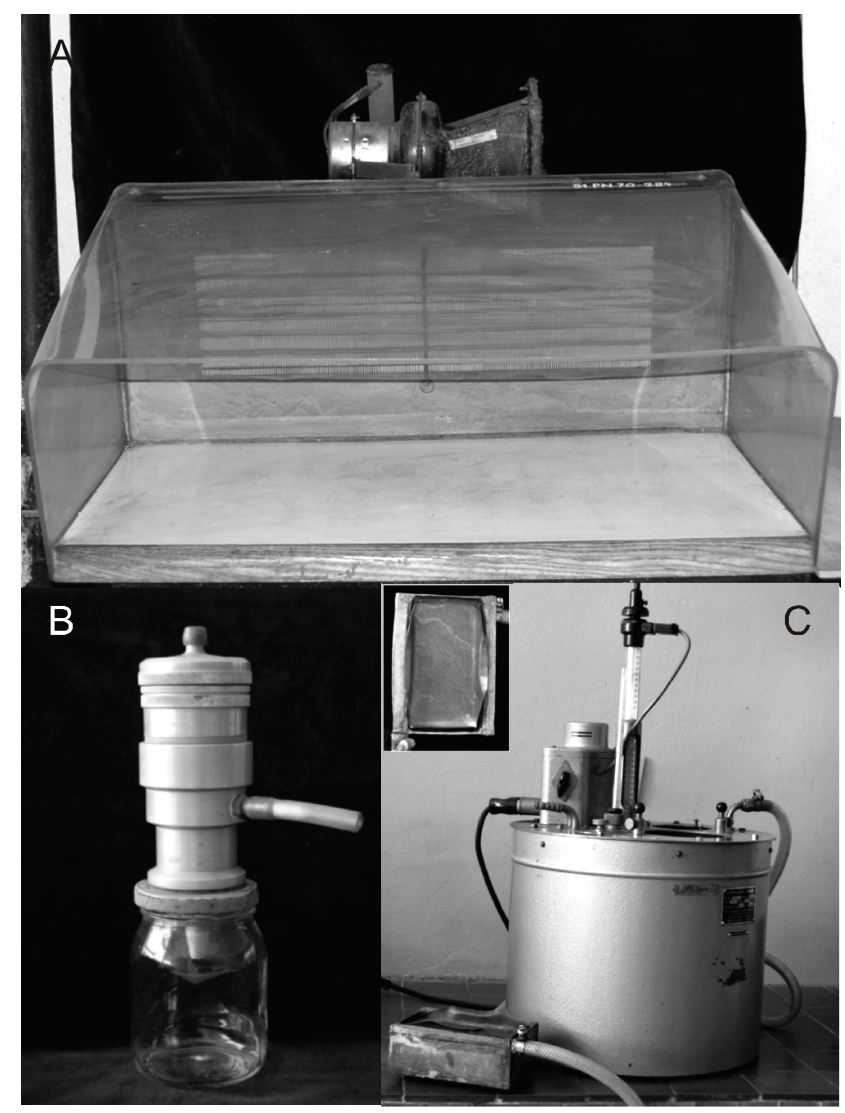

Fig. 1. A) A chamber with laminar airflow constructed by E. Pojnar; B) A device for enzyme filtration constructed by E. Pojnar; C) A device attached to a water bath constructed by E. Pojnar

from the cell wall (Fig. 2A), while freshly isolated protoplasts treated in this way collapsed (Fig. 2B). In a 3-4 day culture in a medium enriched with vitamins and growth regulators (including natural ones such as those of coconut milk) the regenerated cells "budded" (Fig. 2C) - a term first used by Pojnar, and subsequently adopted by his collaborators. A formed bud did not, however, detach from the mother cell, which suggests that cell division did not occur. Observations under an electron microscope revealed that in "naked" protoplasts the surface of the plasma membrane was smooth, while in those with rebuilt cell walls numerous vesicles were visible and dense material was accumulated on the surface of the plasmalemma (Fig. 3A). Also, clusters of fibrillar material could be observed (Fig. 3B). After five days of culturing, the cell wall became clearly apparent (Fig. 3C). Studies exploiting the electron microscope were carried out in collaboration with E.C. Cocking and J.H.M. Willison (Pojnar et al., 1967).

Using plant protoplasts as a very convenient material to study viral infection (exposed plasma membrane is far

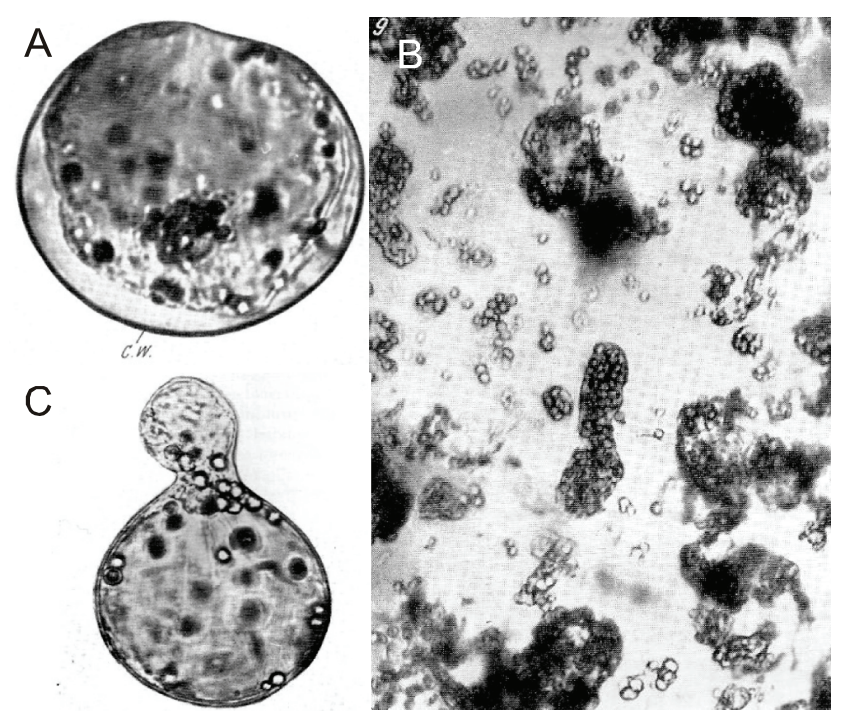

Fig. 2. A) Clearly evident, a new cell wall (C.W.) in frozen and thawed tomato protoplast after short treatment; B) Debris remaining after freezing and thawing of freshly isolated tomato protoplasts; C) Budding of tomato protoplast (Fig. 2A-C - photographs taken from E. Pojnar's postdoctoral dissertation - 1969)

more susceptible to viral infection than plasmalemma protected by a cell wall), Professor Pojnar together with Professor Cocking investigated the penetration of the tobacco mosaic virus (TMV) into isolated protoplasts and the fate of virus particles during cell wall regeneration (Cocking and Pojnar, 1969). Earlier, Cocking (1966) found that viruses enter a protoplast via pinocytosis and then lose their protein envelope, as a result of which viruses in infected protoplasts seem to be much thinner.

The first doctoral thesis that Professor Pojnar supervised focused on the influence of various factors (age, developmental stage, light) and TMV infection on the regeneration capacity of mesophyll tobacco protoplasts (Kobyłko, 1976). Plants of Nicotiana tabacum "Samsun" were infected with TMV ordinary strain, and after three weeks protoplasts were isolated from plants exhibiting symptoms of systemic infection. Already during the isolation differences were detected between healthy and infected material. Protoplasts from the infected leaves required longer incubation with the enzyme, and an initial plasmolysis in a $10 \%$ sucrose was also necessary. Moreover, protoplasts were smaller, with bright yellow chloroplasts that tended to cluster. In protoplasts isolated from plants infected with TMV the presence of crystalline bodies, often in the form of hexagonal plates, was observed (Fig. 4A and Fig. 4B). During the culture differences in size and appearance of protoplasts from 


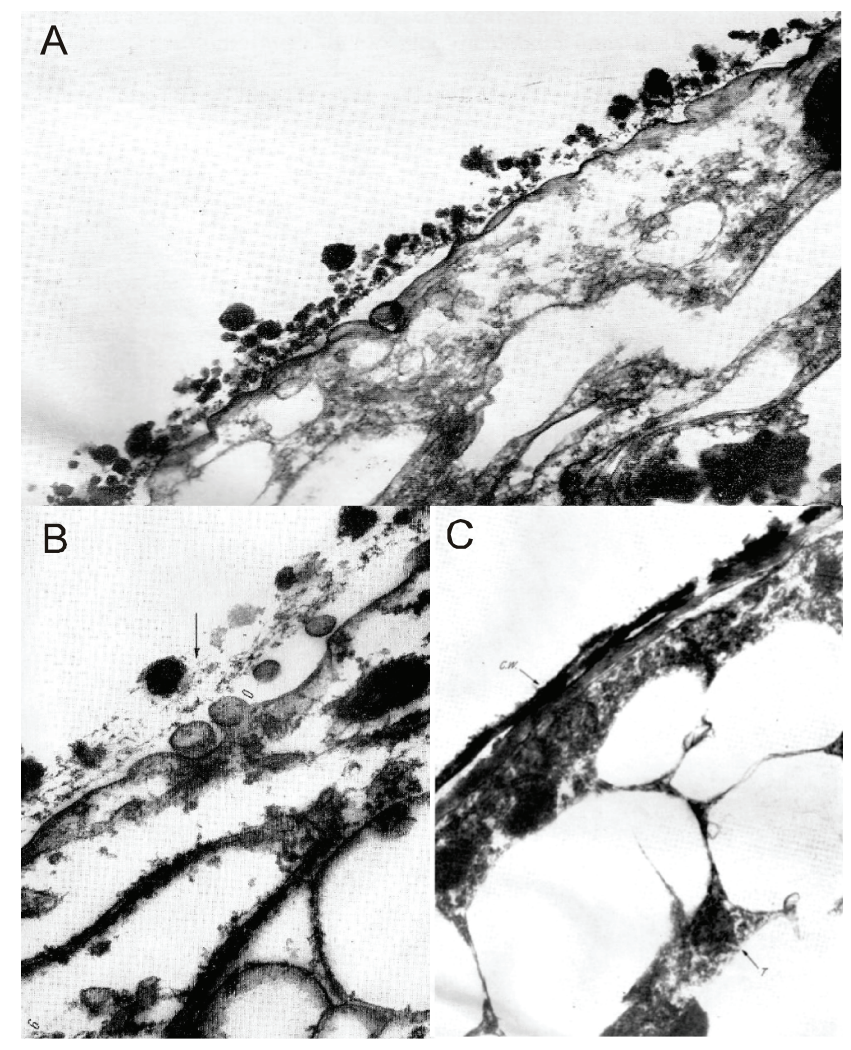

Fig. 3. A) Presence of dense material on the surface of tomato protoplast at an early stage of cell wall regeneration; B) Fibrillar material visible on plasmalemma at an early stage of cell wall regeneration; C) Clearly discernible, a new cell wall (C.W.) of tomato protoplast after 5 days culture (Fig. 3A-C - photographs taken from E. Pojnar's postdoctoral dissertation - 1969)

healthy and infected material gradually evanesced. Protoplasts increased in size, especially those obtained from infected plants. On the fifth day of the culture they were larger than the control group. However, during protoplast regeneration, the presence of inclusion protein bodies caused a significant reduction in cell division. Giant cells were also formed (more than $100 \mu \mathrm{m}$ in diameter, compared with about $60 \mu \mathrm{m}$ for healthy material). Callus obtained from infected material was poorly organogenic and shoot regeneration was not as effective as in callus obtained from healthy material. Studies on virus concentrations have shown significantly more virus particles in differentiating shoot primordia than in undifferentiated callus cells. Moreover, limited rooting of infected shoots was observed. Among plants obtained via indirect organogenesis from TMV-infected protoplasts single virus-free specimens were found. The conclusion of the study was that the virus introduced into the protoplast underwent its regenerative cycle through multi-

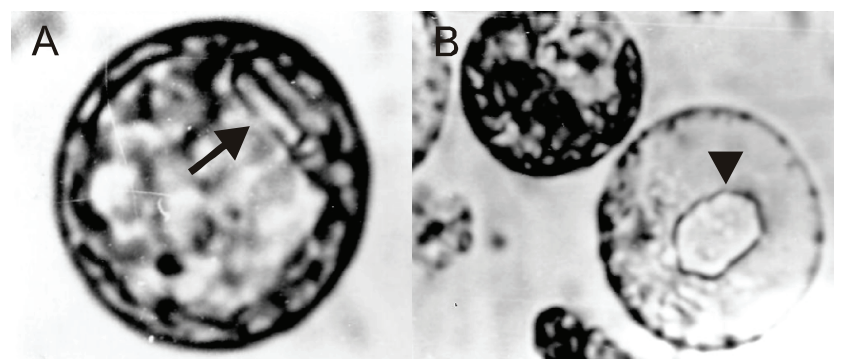

Fig. 4. A) Mesophyll protoplasts of tobacco "Samsun" infected with TMV containing crystalline body (arrow); B) Mesophyll protoplasts of tobacco "Samsun" infected with TMV containing hexagonal plate (arrowhead) (Fig. 4A-B - photographs taken from T. Kobyłko's PhD dissertation - 1976)

plication in plant cells, showing clear signs of systemic TMV infection in most regenerated plants (Kobyłko et al., 1976; Pojnar et al., 1977).

The pioneering studies in the field of mutational breeding were presented in the doctoral thesis prepared by Maria Lech, who investigated the impact of fast neutrons on the viability of tobacco "Xanti" protoplasts, their regenerative potential, and the characteristics of the plants regenerated from irradiated protoplast-derived callus (Lech, 1980). These experiments were the world's first studies exploiting neutrons as mutagenic agents in cultured protoplasts. TMS agar medium (Nagata and Takebe 1971) or a culture of protoplasts embedded in agar TMS medium were irradiated in cyclotron U-120 at the Institute of Nuclear Physics in Cracow. Fast neutrons were obtained in a nuclear reaction owing to the energy of accelerated deuterons. The neutron dose was calculated using a set of tissue-resembling, ionizing chambers (Huczkowski, 1973; Huczkowski and Kubajak, 1976). Among several dosages tested (0.2-1.0 J/kg), 0.2 and $0.5 \mathrm{~J} / \mathrm{kg}$ had a stimulatory effect on shoot formation from protoplast-derived callus, regardless of the irradiation target (embedded protoplasts or medium). However, regenerated shoots rooted less efficiently than in the control treatment. The application of fast neutrons increased the mitotic index in the regenerated plants, although the typical course of the mitosis was often disturbed. A shortening of the prophase, followed by a longer metaphase was observed, as well as chromosomal aberrations: lack of a metaphase plate, chromosome bridges, delayed chromosomes and their fragments (Fig. 5A - Fig. 5C). Plants regenerated from protoplasts treated with fast neutrons had a variety of chromosome 


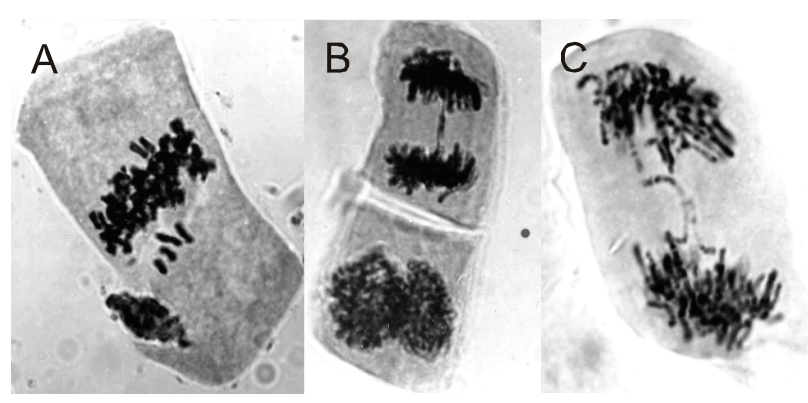

Fig. 5. A) Chromosomal abberation in cells of plant regeneration from irradiated tobacco protoplasts; B) Lack of congretion of four chromosomes; C) Chromosome bridge (Fig. 5A-C - photographs taken from M. Lech's PhD dissertation - 1980)

number, and only half of them were diploids (48 chromosomes), while the rest were aneuploids (26, 27, 28, or 47 chromosomes). Thus, plants had altered morphology and shortened flowering time, as it was also observed in plants derived from seeds or seedlings irradiated with gamma rays (Muszyński, 1968; Malik and Godward, 1975). Interestingly, an increased concentration of nicotine (denoted as the total alkaloids) was detected in regenerants, as in studies conducted by Malepszy et al. (1977) on chemical mutagens, where such changes were probably attributed to genetic variations. Fast neutrons can be used in plant breeding as a mutagen that acts at the level of the single-cell explant, and protoplasts are convenient objects for rapid testing of mutagen action at the micro level.

During the 1970s and 1980s, numerous scientific institutions undertook research into protoplasts of different plant species, mainly from the Solanaceae family, among which tobacco had become virtually a model plant. In our laboratory, as in other domestic and foreign institutions, we focused on tomato protoplast culture and succeeded in developing a regeneration protocol for Lycopersicon glandulosum (no. 731163 originating from the Plant Introduction Station at Ames, Iowa, USA) from seedling mesophyll protoplasts (Lech et al., 1997). By that time Professor Pojnar had already retired, and Professor Kazimierz Miczyński, a virologist, had become the leader of the departmental research group. He proposed exploitation of protoplasts as material in studies on plant susceptibility and resistance to viral pathogens. The studies supervised by him revealed that this wild line was highly tolerant to TSWV (tomato spot wilt virus) infection. Therefore, protoplasts were used as donor material to introduce anti-TSWV genes into tomato cultivars by means of somatic hybridization. Plants obtained in this way exhibited no genetic variations and were all diploid (Pindel et al., 1998). Regeneration of another wild tomato species, $L$. peruvianum, was also successful (Pindel et al., 1998). The next step was to develop optimal conditions for plant regeneration from protoplasts of cultivated tomato ( $L$. esculentum). A study was undertaken on a Polish hybrid variety "Stevens x Rodade" (Pindel et al., 1998). The efficiency of protoplast isolation and regeneration to callus stage was comparable with that obtained for other tomato varieties cultivated in Poland and abroad (Mülbach, 1980; Niedz et al., 1985; Shahin, 1985; Bartoszewski and Zielińska-Dziadczyk, 1994). However, the callus tissue was not organogenic. This confirmed the existing differences in the morphogenetic potential observed among genotypes, as previously discussed (Tan et al., 1987; Patil et al., 1994).

Simultaneously, studies on legume protoplasts were conducted in the Department, followed, a few years later, by studies on monocot protoplasts. Both these groups of plants are regarded as difficult in in vitro culture, due to their susceptibility to stress factors, such as protoplast isolation itself and culture in artificial conditions. In order to develop novel, interesting ornamental forms, protoplast isolation and culture were optimized for tulip, hyacinth, narcissus and Cymbidium orchids (Pindel and Lech, 2002; Pindel, 2007). Isolation and culture protocols were developed for ornamental asparagus naturally resistant to Fusarium pathogens (Pindel, 1997; Pindel, 2002). Attempts have also been made to improve culture conditions for regeneration of legume plants, such as white clover, yellow lupin and grasspea (Pindel, 1990; Czura et al., 2006; Wiszniewska and Pindel, 2009; Wiszniewska and Pindel, 2010a; Piwowarczyk and Pindel, 2011).

At the end of the $20^{\text {th }}$ century scientific interest in protoplasts decreased. Nevertheless, in our laboratory, currently headed by Professor Anna Pindel, such studies are being continued, but their character has been slightly changed. We are trying to identify the potential reasons for monocot and legume susceptibility to protoplast culture at the structural level, especially the structure of the cell wall and cytoskeleton (Wiszniewska and Pindel, 2010b). A similar approach has been undertaken in other laboratories involved in studies on protoplast regeneration, such as a team researching Solanum lycopersi- 
coides protoplasts (Tylicki et al., 2003), or Wojtaszek and his coworkers studying maize protoplasts (Wojtaszek et al., 2007). The development and structure of the cell wall are also under investigation in the protoplast culture of rice (Sharma et al., 2011) and sugar beet (Majewska-Sawka and Munster, 2003). We focus, in particular, on structural changes in protoplasts obtained by application of various enzyme mixtures. The mixtures contain cellulases, with "Onozuka" R-10 from Aspergillus niger being the most frequently used. Moreover, to produce protoplasts from callus or cell suspensions it is necessary to apply more versatile cellulolytic enzymes, exhibiting xylanase activity (Wiszniewska and Pindel, 2010a). Separation of cells is achieved as a result of pectinases and hemicellulases that digest a middle lamella. It has been postulated that various pectinases interact with cells in different phases of the cell cycle and act like "biochemical sorters" (Sinha and Caligari, 2004). The selective digestion of cell wall components may cause rearrangements in cytoskeletal architecture. This may likely be a reason for arrested divisions of protoplast-derived cells, as found for lupin, grasspea and ornamental asparagus, where subsequent mitoses are rarely observed. Our most recent findings on structural changes in protoplast cultures will be presented in a separate paper. Here, we would like to highlight the positive feedback from Polish and foreign scientific institutions on our attempts to determine the potential role of cell components in protoplast susceptibility in legumes and monocots. This encourages us to continue studies on such vulnerable and demanding plant material as the isolated and poorly responding protoplasts.

\section{Conclusions}

Previously, isolated protoplasts were regarded as a new protoplast-to-plant system for genetic mani-pulation. Nowadays, because of public opposition (especially in Europe), they are a rather convenient material for somatic hybridization, cybridization, protoclonal variability, or proteomics and metabolomics. In most studies exploiting plant protoplasts it is essential to develop efficient methods for the isolation of viable protoplasts of high morphogenetic potential and the regeneration of complete plants. Although significant progress in this field of research has been achieved, there are still economically important plant species, valuable objects of modern agri- culture, which are resistant to protoplast-based technology. Therefore a number of laboratories, including our team at the Department of Botany and Plant Physiology in Krakow, inspired by the pioneering achievements of Professor Edward Pojnar, continue the attempts to understand and eliminate the existing barriers to protoplast regeneration.

\section{References}

Bartoszewski G., Zielińska-Dziadczyk E. (1994) Evaluation of tomato (Lycopersicon esculentum Mill) varieties and lines in hypocotyl, cotyledon and leaves explants and protoplasts culture. (in Polish) Potential in vitro culture application in modern plant breeding. Abstracts VII Ogólnopolska Konferencja Kultur In Vitro Katowice-Ustroń: 48.

Cocking E.C. (1966) An electron microscopic study of the initial stages of infection of isolated tomato fruit protoplasts by tobacco mosaic virus. Planta 68: 206-214.

Cocking E.C., Pojnar E. (1969) An electron microscopic study of the infection of isolated tomato fruit protoplasts by tobacco mosaic virus. J. Gen. Virol. 4: 305-312.

Czura A., Pindel A., Lech M. (2006) Trial of breaking biological barriers in regeneration of yellow lupin protoplasts. (in Polish) Rola Biotechnologii $w$ Rolnictwie. Ed. AR w Krakowie: 47-53.

Huczkowski J. (1973) Studies on application of cyclotron $U-120$ and fast neutrons generator to radiation induction of mutagenesis in plants. (in Polish) Hod. Roślin Aklim. Nasien. 17: 145-159.

Huczkowski J., Kubajak A. (1976) Application of fast neutrons to radiation mutagenesis of pea. (in Polish) Raport IFJ Kraków No 931/B: 3-25.

Kobyłko T. (1976) Influence of some endogenous factors and light on regeneration abilities of protoplasts isolated from tobacco (Nicotiana tabacum L.) leaves. (in Polish) PhD thesis.

Kobyłko T., Pojnar E., Przyłuska M. (1976) Growth and differentiation of cells regenerated from protoplasts isolated from TMV infected tobacco leaves. (in Polish) Zesz. Prob. Post. Nauk Roln. 182: 9-15.

Lech M. (1980) Influence of fast neutrons on features of plants obtained from irradiated protoplasts isolated from leaves of tobacco (Nicotiana tabacum L.). (in Polish) PhD thesis.

Lech M., Pindel A., Miczyński K. (1997) Plant regeneration from protoplasts obtained from mesophyll leaf tissue of Lycopersicon glandulosum C. H. Mull. Acta Biol. Cracoviensa Ser. Botanica 39: 51-54.

Majewska-Sawka A., Munster A. (2003) Cell-wall antigens in mesophyll cells and mesophyll-derived protoplasts of sugar beet - possible implication in protoplast recalcitrance?Plant Cell Rep. 21: 946-954.

Malepszy S., Corduan G., Przybecki Z. (1977) Variability in the level of alkaloids in Nicotiana sylvestris Spegoszz et 
Comes plants after mutagenesis in vitro. Bull. Acad. Polon. Sci. 25: 737-740.

Malik I.A., Godward M.B.E. (1975) Effects of gamma irradiation on the seeds of $N$. tabacum. Pakistan J. Sci. Res. 27: $13-20$.

Muszyński S. (1968) Mutation in Petunia III. Morphological changes observed in $M_{1}$ and $M_{2}$ generations after irradiation of seeds. Acta Soc. Bot. Pol. 37: 593-599.

Mülbach H.P. (1980) Different regeneration potentials of mesophyll protoplasts from cultivated and wild species of tomato. Planta 148: 89-96.

Nagata T., Takebe J. (1971) Plating of isolated tobacco mesophyll protoplasts on agar medium. Planta 99: 12-20.

Niedz R.P., Rutter S.M., Handley L.W., Sink K.C. (1985) Plant regeneration from leaf protoplasts of six tomato cultivars. Plant Sci. 39: 199-204.

Patil R.S., Davey M.R., Power J.B. (1994) Highly efficient plant regeneration from mesophyll protoplasts of Indian field cultivars of tomato (Lycopersicon esculentum). Plant Cell Tiss. Org. Cult. 36: 225-258.

Pindel A. (1990) Conditions for cultivating protoplasts of white clover (Trifollium repens L. cv. Podkowa). (in Polish). Zesz. Nauk. AR w Krakowie. Ogrodnictwo 19: 45-61.

Pindel A. (1997) Preliminary experiments on the isolation of protoplasts of ornamental asparagus (Asparagus densiflorus Jesson 'Sprengeri'). (in Polish) Zesz. Nauk. AR w Krakowie. Ogrodnictwo 23: 73-80.

Pindel A. (2002) Studies of protoplast culture from callus of Asparagus densiflorus 'Sprengeri'. Folia Hort. 14(2): 243250.

Pindel A. (2007) Optimization of isolation conditions of Cymbidium protoplasts. Folia Hort.19(2): 79-88.

Pindel A., Lech M. (2002) Influence of the explants, selection on yield of protoplasts from some ornamental species of monocotyledonous plants. (in Polish) Zesz. Probl. Post. Nauk Roln. 488: 571-576.

Pindel A., Lech M., Miczyński K. (1998a) Regeneration of leaf mesophyll protoplasts from Lycopersicon glandulosum, $L$. peruvianum and L. esculentum Stevens $x$ Rodade hybrid. Acta Biol. Cracoviensa Ser. Botanica 40: 41-46.

Pindel A., Lech M., Surówka J. (1998b) Description of regenerated from protoplasts Lycopersicon glandulosum plants. (in Polish). Zesz. Nauk. AR w Krakowie 57: 269-272.

Piwowarczyk B., Pindel A. (2011) Isolation and culture of grasspea (Lathyrus sativus L.) protoplasts - studies on viability and cell wall reconstruction. Abstracts of the IV Congress of Polish Biotechnology and "IV EUROBIOTECH 2011" Central European Congress of Life Sciences Kraków, Poland 12th-15th October: 101.
Pojnar E. (1969) Studies on the protoplasts isolated from tomato fruit. (in Polish) Zeszyty Naukowe WSR w Krakowie. Rozprawy16: 1-49.

Pojnar E., Cocking E.C. (1968) Formation of cell aggregates by regenerating isolated tomato fruit protoplasts. Nature 218: 289-291.

Pojnar E., Kobyłko T., Lech M. (1977) Regeneration of tobacco (Nicotiana tabacum v. Samsun) plants from tobacco mosaic virus infected protoplasts. (in Polish) Zesz. Prob. Post. Nauk Roln. 195: 23-26.

Pojnar E., Willison J.H., Cocking E.C. (1967) Cell wall regeneration by isolated tomato fruit protoplasts. Protoplasma 64: 460-480.

Shahin E.A. (1985) Totipotency of tomato protoplasts. Theor. Appl. Genet. 69: 235-240.

Sharma R., Tan F., Jung K.-H., Sharma M.K., Peng Z., Ronald P.C. (2011) Transcriptional dynamics during cell wall removal and regeneration reveals key genes involved in cell wall development in rice. Plant Mol. Biol. 77: 391-406.

Sinha A., Caligari P.D.S. (2004) Aspects of isolation underpinning mitotic behavior in lupin protoplasts. Austral. J. Bot. 52: 669-676.

Tan M.M.C., Rietveld E.M., van Marrevijk G.A., Kool A.J. (1987) Regeneration of leaf mesophyll protoplasts of tomato cultivars (L. esculentum): factors important for efficient protoplast culture and plant regeneration. Plant Cell Rep. 6: 172-175.

Tylicki A., Burza W., Malepszy S., Kuraś M. (2003) Changes in the organization of the tubulin cytoskeleton during the early stages of Solanum lycopersicoides Dun. protoplast culture. Plant Cell Rep. 22: 312-319.

Wiszniewska A., Pindel A. (2009) Improvement of Lupinus luteus (Fabaceae) protoplast culture - stimulatory effect of agarose embedding and chemical nursing on protoplast divisions. Austral. J. Bot. 57: 501-511.

Wiszniewska A., Pindel A. (2010a) Protoplast culture utilization in studies on legume crops. Acta Agric. Scandinavica Section B - Soil and Plant Science 60: 389-399.

Wiszniewska A., Pindel A. (2010b) Cellular aspects of regeneration in protoplast culture of yellow lupin (Lupinus luteus L.). (in Polish) Biotechnologia 2(89): 18-22.

Wojtaszek P., Baluska F., Kasprowicz A., Łuczak M., Volkmann D. (2007) Domain-specific mechanosensory transmission of osmotic and enzymatic cell wall disturbances to the action cytoskeleton. Protoplasma 230: 217-230. 